popular. Further studies on factors influencing health information sharing behaviour and cross disciplinary research involving healthcare professionals and social media marketers will increase understanding of effective use of SNSs for mass dissemination of information.

\title{
KNOWLEDGE, ATTITUDE AND PRACTICE ON DENGUE AMONG ADULT POPULATION IN FELDA SUNGAI PANCHING TIMUR, KUANTAN, PAHANG.
}

Karimah Hanim AA, Razman MR, Jamalludin AR, Nasreen EH, Htike Myat Phyu, SweSwe L, Hazifah P.

Department of Community Medicine, Kulliyyah of Medicine, International Islamic University Malaysia, Kuantan, Pahang, Malaysia

Introduction: With increasing number of dengue cases in Malaysia, it's of utmost importance that immediate action be taken to limit the epidemic. Since dengue control is a behavioural problem, the knowledge, attitude and practice in population needs to be studied in order to control the disease. Objective: The aim of this study is to assess knowledge, attitude and practice regarding dengue and its associated factors among adult residents of Felda Sungai Panching Timur (SPT), Kuantan, Pahang, 2014.

Methodology: A cross sectional study was carried out involving 265 adult respondents. A face to face interview questionnaire which was divided into 2 parts (Part A: Sociodemographic; Part B: Knowledge, Attitude and Practice) was used. Data was analysed using descriptive statistics, simple and multiple logistic regression.

Results: $53.2 \%$ of the respondents had good knowledge about dengue and it was found that the main source of information was from mass media (76.6\%). However, only 43.4\% were found to have good attitude towards dengue. Multiple Logistic Regression analysis showed that there was no association between sociodemographic characteristics with the level of knowledge and attitude towards dengue. There was also no association found between knowledge of dengue and the attitude of the respondents towards dengue. Descriptive analysis on the practice of dengue showed majority of the respondents who had possible breeding site for Aedes mosquitos (water container, drains/gutter roof/flower pots/ tires) in their compound practiced good habit in preventing the Aedes mosquitoes from breed.

Conclusion: Although knowledge and practice towards dengue is good, their attitude require improvement.

\section{Review}

\section{KNOWLEDGE, ATTITUDE AND PRACTICE of MEDICAL PERSONNEL ON SMOKING CESSATION GUIDELINES: A REVIEW ON ASSOCIATIONS AND QUESTIONNAIRES} ShaifulEhsan $\mathrm{SM}^{1}$, MohdAznan $M A^{1}$, Mohamad Haniki $N M^{2}$, Razman $\mathrm{MR}^{3}$, NA Jamani ${ }^{1}$

\footnotetext{
${ }^{1}$ Department of Family Medicine, Kulliyyah of Medicine, IIUM. ${ }^{2}$ Department of Pharmacy Practice, Kulliyyah of Pharmacy, IIUM. ${ }^{3}$ Department of Community Medicine, Kulliyyah of Medicine, IIUM
}

Number of active smokers in Malaysia is increasing despite availability of stop smoking clinics and smoking cessation medications. Other than smokers' level of motivation to quit smoking, competency of the healthcare professionals involved in providing smoking cessation intervention using evidence-based guidelines needs to considered. Hence, knowledge, attitude and practice (KAP) of the healthcare providers in relation to existing clinical practice guidelines on smoking cessation should be assessed. In this review, we look at the factors contributing to the KAP of medical personnel on the guidelines and also the previous available assessment tool, mainly in the form of a validated questionnaire, for the purpose of applying it to the context of the Malaysian healthcare providers. 